\title{
Effect of strong acid on the self-oscillating behavior for the polymer chain with the $\mathrm{Fe}(\mathrm{bpy})_{3}$
}

\author{
Tomoka Nakazumi ${ }^{1}$ and Yusuke Hara ${ }^{1, a *}$ \\ ${ }^{1}$ Research Institute for Sustainable Chemistry, ISC, National Institute of Advanced Industrial \\ Science and Technology, AIST, Central 5-2, 1-1-1 Higashi, Tsukuba 305-8565, Japan. \\ ay-hara@aist.go.jp
}

Keywords: $\mathrm{Fe}(\mathrm{bpy})_{3}$, Self-oscillation, Period, Amplitude, BZ reaction, Polymer chain

\begin{abstract}
In this study, a self-oscillating polymer chain with $\mathrm{Fe}(\mathrm{bpy})_{3}$ as the catalyst of the Belouzov-Zhabotinsky (BZ) reaction was synthesized to examine the influence of strong acid (due to its oxidizing power) on the self-oscillating behavior. The polymer chain with $\mathrm{Fe}(\mathrm{bpy})_{3}$ underwent a soluble-insoluble self-oscillation induced by the BZ reaction because the solubilities of the $\mathrm{Fe}(\mathrm{bpy})_{3}$ moiety in the reduced and oxidized states were different. The self-oscillation of the polymer chain with $\mathrm{Fe}(\mathrm{bpy})_{3}$ lasted a long time. During the long period of the self-oscillation, the oscillating period and amplitude of the self-oscillation were stable.
\end{abstract}

\section{Introduction}

In previous studies, self-oscillating polymer systems with a $\mathrm{Ru}$ catalyst moiety $\left(\mathrm{Ru}(\mathrm{bpy})_{3}\right)$ such as the Belouzov-Zhabotinsky (BZ) reaction [1-6] were developed [7-14]. The polymer chain with $\mathrm{Ru}(\text { bpy })_{3}$ undergoes a soluble-insoluble self-oscillation induced by the BZ reaction under constant temperature conditions. In the $\mathrm{BZ}$ reaction, the redox state of the $\mathrm{Ru}(\mathrm{bpy})_{3}$ moiety in the polymer chain changes periodically and the solubility of the polymer chain changes at the same time because the oxidized and reduced states of $\mathrm{Ru}(\mathrm{bpy})_{3}$ have different solubilities. To apply the self-oscillating polymer system to devices such as an autonomous pump system, the cost of the Ru(bpy) 3 moiety was regarded a problem because $\mathrm{Ru}$ is a rare metal. To reduce the cost of the metal catalyst moiety in the self-oscillating polymer system, Hara et al. first synthesized a self-oscillating polymer chain with an $\mathrm{Fe}$ catalyst moiety $\left(\mathrm{Fe}(\mathrm{bpy})_{3}\right)$ for the $\mathrm{BZ}$ reaction $[15,16]$. In this study, the optical self-oscillating behaviors of the polymer chain with $\mathrm{Fe}(\mathrm{bpy})_{3}$ were measured at constant concentrations of the three $\mathrm{BZ}$ substrates (malonic acid (MA; $0.1 \mathrm{M})$, sodium bromate $\left(\mathrm{NaBrO}_{3} ; 0.2\right.$ $\mathrm{M})$, and sulfuric acid $\left(\mathrm{H}_{2} \mathrm{SO}_{4} ; 0.2 \mathrm{M}\right)$ ) and at constant several temperatures $(T=11,12,13,15,17$, and $19^{\circ} \mathrm{C}$ ). In previous studies $[15,16]$, nitric acid was used as the strong acidic agent for the BZ reaction. In this study, we selected sulfuric acid as the strong acidic agent to confirm the influence of the oxidation power on the self-oscillating behavior of the polymer solution with $\mathrm{Fe}(\mathrm{bpy})_{3}$.

\section{Experimental Section}

Synthesis of Poly(NIPAAm-co-Fe(bpy $\left.)_{3}\right)$. The polymer chain with $\mathrm{Fe}(\mathrm{bpy})_{3}$ was synthesized by radical polymerization with a total monomer concentration of $20 \mathrm{wt} \%$ (NIPAAm $(9.0 \mathrm{~g})$ and $\left.\left[\mathrm{Fe}(\mathrm{bpy})_{3}\right](1.0 \mathrm{~g})\right)$, utilizing $2,2^{\prime}$-azobis-(2-methylbutyronitrile) $(0.01 \mathrm{~g})$ as an initiator, at $80{ }^{\circ} \mathrm{C}$ for $5 \mathrm{~h}$ under $\mathrm{N}_{2}$ bubbling. After synthesis, the reaction mixture solution was dialyzed for $30 \mathrm{~d}$ while changing ethanol frequently. The dialyzed poly(NIPAAm-co-Fe(bpy $\left.)_{3}\right)$ solution was freeze-dried after replacing ethanol with water.

Measurement of the Absorbance of Poly(NIPAAm-co-Fe(bpy) $)_{3}$. To clarify the isosbestic point of the poly(NIPAAm-co-Fe(bpy) ${ }_{3}$ ) solution, we measured the absorbance of the polymer chain as a function of the wavelengths in the reduced and oxidized states. To measure the reduced state, the $0.2 \mathrm{wt} \%$ polymer solution with $\mathrm{Fe}(\mathrm{bpy})_{3}$ contained $0.2 \mathrm{M}$ sodium chloride $(\mathrm{NaCl}), 0.1 \mathrm{M}$ malonic acid (MA), and $0.2 \mathrm{M}$ sulfuric acid $\left(\mathrm{H}_{2} \mathrm{SO}_{4}\right)$. In the oxidized state, the polymer solution $(0.2 \mathrm{wt} \%)$ 
contained $0.1 \mathrm{M} \mathrm{NaCl}, 0.2 \mathrm{M}$ sodium bromate $\left(\mathrm{NaBrO}_{3}\right)$, and $0.2 \mathrm{M} \mathrm{H}_{2} \mathrm{SO}_{4}$. The ionic strength of the polymer solution was adjusted using $\mathrm{NaCl}$ to be the same in the reduced and oxidized states.

\section{Measurement of the Lower Critical Solution Temperature (LCST)}

The lower critical solution temperature (LCST) for the polymer chain with $\mathrm{Fe}(\mathrm{bpy})_{3}$ in the reduced and oxidized states was measured via the isosbestic point measurement $(604 \mathrm{~nm}$ wavelength). The LCSTs in the reduced and oxidized state were monitored by UV-vis spectrophotometry at temperatures ranging from 13 to $60{ }^{\circ} \mathrm{C}$. In the reduced state, the $0.2 \mathrm{wt} \%$ polymer solution contained $0.2 \mathrm{M} \mathrm{NaCl}, 0.1 \mathrm{M}$ malonic acid (MA), and $0.2 \mathrm{M} \mathrm{H}_{2} \mathrm{SO}_{4}$. In the oxidized state, the polymer solution $\left(0.2 \mathrm{wt} \%\right.$ ) contained $0.1 \mathrm{M} \mathrm{NaCl}, 0.2 \mathrm{M} \mathrm{NaBrO}_{3}$, and $0.2 \mathrm{M}$ $\mathrm{H}_{2} \mathrm{SO}_{4}$. $\mathrm{NaCl}$ was utilized to adjust the ionic strength of the polymer solution in the reduced and oxidized states.

\section{Measurement of Transmittance Self-Oscillations}

To measure the self-oscillation induced by the $\mathrm{BZ}$ reaction, the $0.2 \mathrm{wt} \%$ poly(NIPAAm-co-Fe(bpy) $)_{3}$ ) solutions including the three $\mathrm{BZ}$ substrates (MA (0.1 M), $\mathrm{NaBrO}_{3}(0.2$ $\mathrm{M})$, and $\mathrm{H}_{2} \mathrm{SO}_{4}(0.2 \mathrm{M})$ ) were prepared. As shown in Fig. 1, poly(NIPAAm-co-Fe(bpy) ${ }_{3}$ ) solution has an isosbetic point at $604 \mathrm{~nm}$. This wavelength was different from the previous investigation because the polymer concentration, the strong acid and the concentrations of the oxidizing and reducing agents were different [15]. In this study, we used the $604 \mathrm{~nm}$ wavelength at several temperatures $\left(T=11,12,13,15,17\right.$ and $\left.19^{\circ} \mathrm{C}\right)$. The time course of the self-oscillation at $604 \mathrm{~nm}$ was monitored using a UV spectrophotometer.

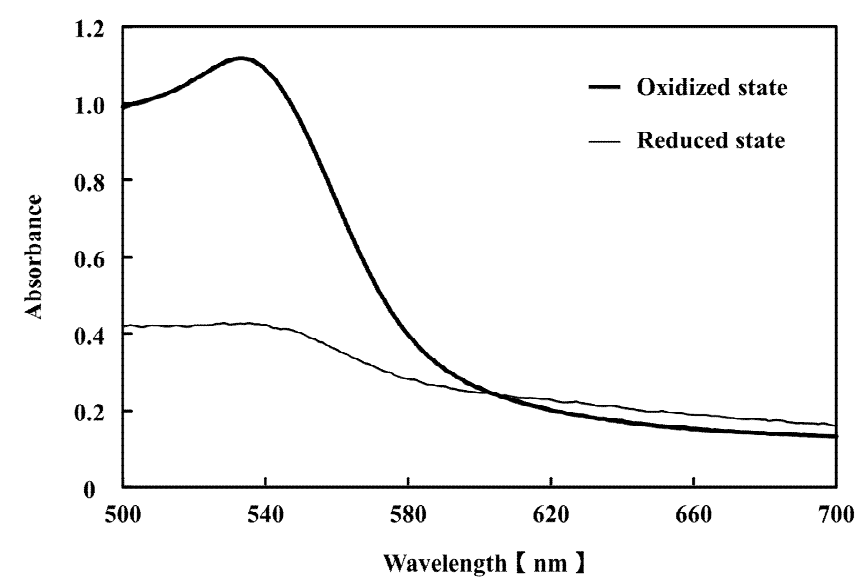

Fig. 1. Relationship between absorbance and the wavelength of the $0.2 \mathrm{wt} \%$

poly(NIPAAm-co-Fe(bpy) $)_{3}$ ) solutions in the reduced and oxidized states. MA and $\mathrm{NaBrO}_{3}$ were used as the reducing and oxidizing agents, respectively. The ionic strength was adjusted to the same level in the reduced and oxidized state using $\mathrm{NaCl}$.

\section{Results and Discussion.}

Fig. 1 shows the relationship between the wavelength and the absorbance of the poly(NIPAAm-Co-Fe(bpy $)_{3}$ ) solutions in the reduced and oxidized states. As shown in Fig. 1, the isosbestic point of the polymer solution with sulfuric acid as the strong acid agent for the BZ reaction was $604 \mathrm{~nm}$. In this study, all measurements to measure the soluble-insoluble self-oscillation of the polymer solution were at $604 \mathrm{~nm}$; this ignored the color change self-oscillation because the colors of $\mathrm{Fe}(\mathrm{bpy})_{3}$ in the reduced and oxidized states are different.

The LCST of the polymer solutions in the reduced and oxidized states (see Fig. 2) were measured at $604 \mathrm{~nm}$ while changing the temperature from $13{ }^{\circ} \mathrm{C}$ to $60{ }^{\circ} \mathrm{C}$. In this LCST measurement, $\mathrm{MA}$ and $\mathrm{NaBrO}_{3}$ were adopted as the reduced and oxidized agents, respectively. The 
ionic strength of the $0.2 \mathrm{wt} \%$ polymer solution was adjusted using $\mathrm{NaCl}$ because the ionic strength of the solution affects the LCST and the transmittance self-oscillating behavior [15]. The LCST in the reduced state was about $28^{\circ} \mathrm{C}$ and that in the oxidized state was about $15{ }^{\circ} \mathrm{C}$.

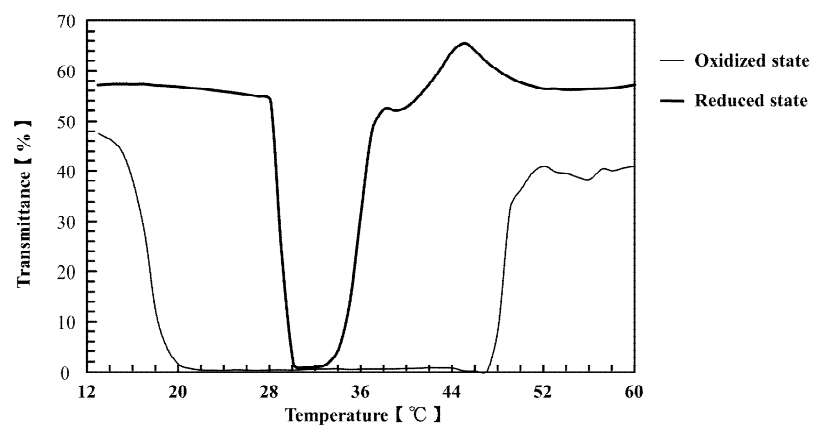

Fig. 2 Temperature dependence $\left(13-60^{\circ} \mathrm{C}\right)$ of transmittance at $604 \mathrm{~nm}$ for poly(NIPAAm- $\mathrm{co}-\mathrm{Fe}(\mathrm{bpy})_{3}$ ) solutions in the reduced and oxidized states.

In this study, we measured the transmittance self-oscillation of a 0.2 wt\% poly(NIPAAm-co-Fe(bpy) ${ }_{3}$ ) solution at constant concentrations of $\mathrm{NaBrO}_{3}, \mathrm{MA}$, and $\mathrm{H}_{2} \mathrm{SO}_{4}$, at different temperatures $\left(\mathrm{T}=11,12,13,15,17\right.$, and $19^{\circ} \mathrm{C}$ ). At 15,17 , and $19{ }^{\circ} \mathrm{C}$, there were no observations of transmittance self-oscillation. The LCST of the $0.2 \mathrm{wt} \%$ poly(NIPAAm- $\left.\mathrm{co}-\mathrm{Fe}(\mathrm{bpy})_{3}\right)$ solution in the oxidized state was about $15{ }^{\circ} \mathrm{C}$. This result indicated that the polymer chain in the oxidized state above $15{ }^{\circ} \mathrm{C}$ had hydrophobic nature. The transmittance self-oscillation originates in the soluble-insoluble periodic change of the $\mathrm{Fe}(\mathrm{bpy})_{3}$ moiety in the polymer chain. When the solubility of the polymer main-chain decreased in the oxidized state, the polymer chain easily aggregated. We consider that the decreasing flexibility of the polymer chain due to the low solubility inhibited the transmittance self-oscillation. Therefore, the self-oscillation could not be measured at temperatures above $15^{\circ} \mathrm{C}[15]$.
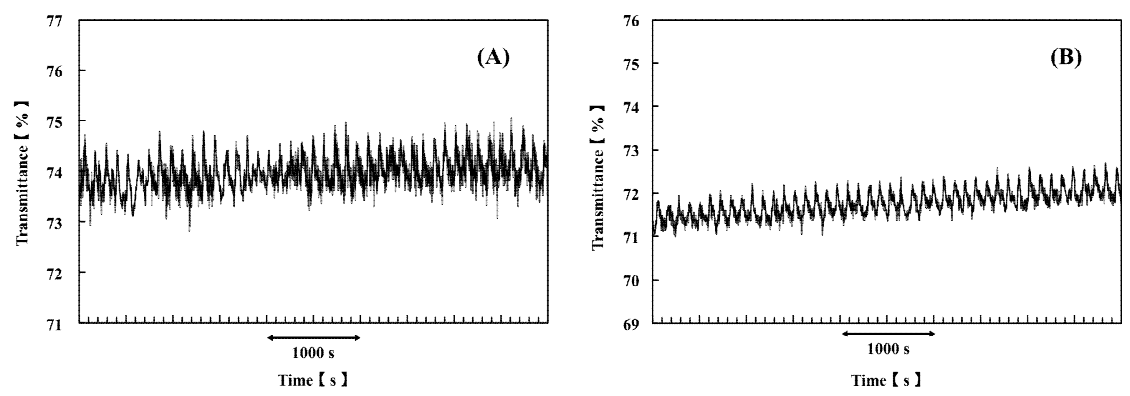

Fig. 3 Transmittance self-oscillation for $0.2 \mathrm{wt} \%$ poly(NIPAAm-co-Fe(bpy $)_{3}$ ) solutions at constant sulfuric acid, sodium bromate, and malonic acid condition $\left(\left[\mathrm{H}_{2} \mathrm{SO}_{4}\right]=0.2 \mathrm{M},\left[\mathrm{NaBrO}_{3}\right]=0.2 \mathrm{M}\right.$,

$$
[\mathrm{MA}]=0.1 \mathrm{M}):(\mathrm{A}) 12{ }^{\circ} \mathrm{C},(\mathrm{B}) 13{ }^{\circ} \mathrm{C} \text {. }
$$

Fig. 4 shows the amplitude of the transmittance self-oscillation for the poly(NIPAAm-co-Fe(bpy) $)_{3}$ ) solution at constant concentrations of the BZ substrates at 12 and $13{ }^{\circ} \mathrm{C}$. The amplitude of the self-oscillation at $12{ }^{\circ} \mathrm{C}$ was slightly larger than that at $13{ }^{\circ} \mathrm{C}$ (Fig. 4). In this self-oscillating condition, the polymer flexibility increased when decreasing the temperature because the LCST in the oxidized state of the polymer chain was about $15{ }^{\circ} \mathrm{C}$. Therefore, we considered that the amplitude of the self-oscillation at $12{ }^{\circ} \mathrm{C}$ was slightly larger than at $13{ }^{\circ} \mathrm{C}$.

Fig. 5 shows the time dependence of the period of the transmittance self-oscillation for the 0.2 wt $\%$ poly(NIPAAm-co-Fe(bpy) $)_{3}$ ) polymer solution at constant concentrations of the three BZ substrates. The period of the self-oscillation was almost the same $(120 \mathrm{~s})$ because the self-oscillating period follows the Arrhenius equation [17]. 

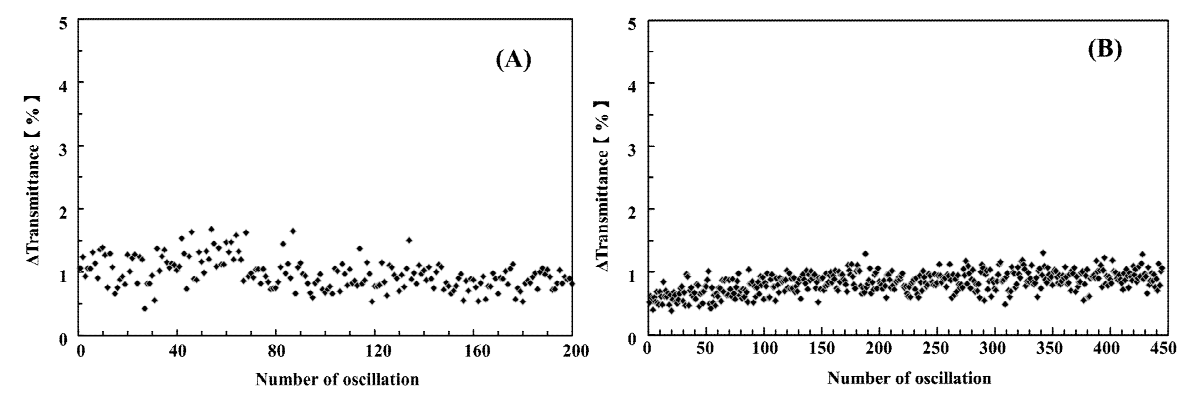

Fig. 4 Dependence of the amplitude of optical self-oscillation for $0.2 \mathrm{wt} \%$ poly(NIPAAm-co-Fe(bpy) $\left.)_{3}\right)$ at constant sulfuric acid, sodium bromate, and malonic acid $\left(\left[\mathrm{H}_{2} \mathrm{SO}_{4}\right]=\right.$ $\left.0.2 \mathrm{M},\left[\mathrm{NaBrO}_{3}\right]=0.2 \mathrm{M},[\mathrm{MA}]=0.1 \mathrm{M}\right):(\mathrm{A}) 12{ }^{\circ} \mathrm{C},(\mathrm{B}) 13{ }^{\circ} \mathrm{C}$.
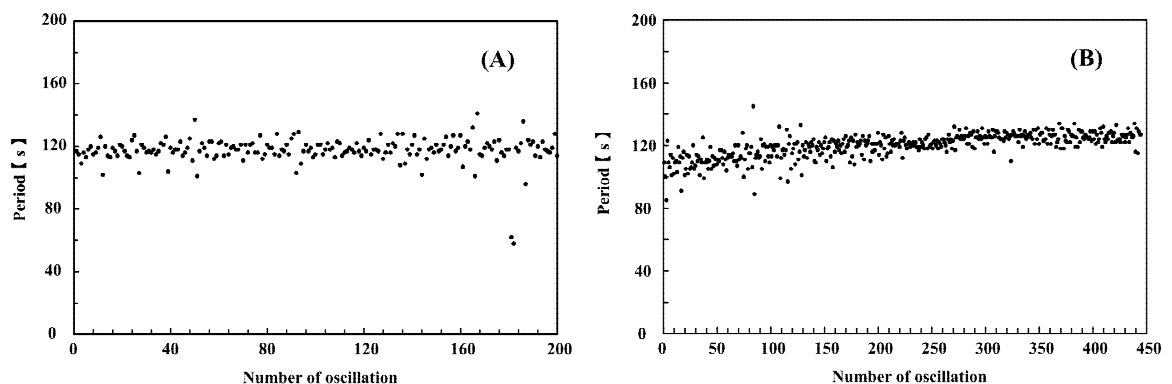

Fig. 5 Dependence of the period of optical self-oscillation for $0.2 \mathrm{wt} \%$ poly(NIPAAm-co-Fe(bpy $\left.)_{3}\right)$ at constant sulfuric acid, sodium bromate, and malonic acid $\left(\left[\mathrm{H}_{2} \mathrm{SO}_{4}\right]=0.2 \mathrm{M},\left[\mathrm{NaBrO}_{3}\right]=0.2 \mathrm{M}\right.$,

$$
[\mathrm{MA}]=0.1 \mathrm{M}):(\mathrm{A}) 12{ }^{\circ} \mathrm{C},(\mathrm{B}) 13{ }^{\circ} \mathrm{C} \text {. }
$$

\section{Conclusion}

The transmittance self-oscillation of the $0.2 \mathrm{wt} \%$ poly(NIPAAm-co-Fe(bpy $\left.)_{3}\right)_{\text {solution was }}$ observed at 11,12 , and $13{ }^{\circ} \mathrm{C}$. There was no observation of the transmittance self-oscillation above $15{ }^{\circ} \mathrm{C}$ because the LCST of the oxidized polymer solution was about $15{ }^{\circ} \mathrm{C}$. Using sulfuric acid as the strong acid agent in the BZ reaction affected the solubility of the polymer chain with the $\mathrm{Fe}(\text { bpy })_{3}$ because the LCST in the oxidized state changed compared relative to the use of nitric acid. The self-oscillation of the $0.2 \mathrm{wt} \%$ poly(NIPAAm-co-Fe(bpy) $)_{3}$ ) solution had a long lifetime with stable amplitude and period.

\section{Acknowledgments}

This work was supported by Grants-in-Aid (KAKENHI) for Young Scientists (B) (16K17493, 15K18014), and Scientific Research (B) (15H03827).

\section{References}

[1] A. N. Zaikin, A. M. Zhabotinsky, Concentration wave propagation in two-dimensional liquidphase self-oscillating system. Nature 225 (1970) 535-537.

[2] R. J. Field, E. Koros, R. M. Noyes, Oscillations in Chemical Systems II. Thorough analysis of temporal oscillations in the bromate-cerium-malonic acid system. J. Am. Chem. Soc. 94 (1972) 8649-8664.

[3] E. J. Reusser, R. J. Field, The Transition from phase waves to trigger waves in a model of the Zhabotinsky reaction. J. Am. Chem. Soc. 101 (1979) 1063-1094.

[4] S. K. Scott, Chemical Chaos, 1st ed.; Oxford University Press, Oxford, UK, 1991. 
[5] J. J. Tyson, P. C. Fife, Target patterns in a realistic model of the Belousov-Zhabotinskii reaction. 73 (1980) 2224-2237.

[6] R. J. Field, M. Burger, Oscillations and Traveling Waves in Chemical Systems, John Wiley \& Sons, New York, 1985.

[7] T. Ishiwatari, M. Kawaguchi, M. Mitsuishi, Oscillatory reactions in polymer systems. J. Polym. Sci. Part A: Polym. Chem. 22 (1984) 2699-2704.

[8] R. Yoshida, T. Sakai, S. Ito, T. Yamaguchi, Self-oscillation of polymer chains with rhythmical soluble-insoluble changes. J. Am. Chem. Sci. 124 (2002) 8095-8098.

[13] Y. Hara, R. Yoshida, Self-oscillation of polymer chains induced by the Belousov-Zhabotinsky reaction under acid-Free conditions. J. Phys. Chem. B 109 (2005) 9451-9454.

[14] Y. Hara, R. Yoshida, Self-oscillating polymer fueled by organic acid. J. Phys. Chem. B 112 (2008) 8427-8429.

[15] Y. Hara, R. Yoshida, Damping behavior of aggregation-disaggregation self-oscillation for a polymer chain. Marcomol. Rapid Commun. 30 (2009) 1656-1662.

[12] Y. Hara, Autonomous oscillation of nonthermoresponsive polymers and gels induced by the Belousov-Zhabotinsky reaction. Chemosensors 1 (2013) 3-20.

[13] Y. Hara, H. Mayama, K. Morishima, Generative force of self-oscillating gel. J. Phys. Chem. B 118 (2014) 2576-2581.

[14] Y. Hara, Y. Yamaguchi, H. Mayama, Switching the BZ reaction with a strong-acid-free Gel. J. Phys. Chem. B 118 (2014) 634-638.

[15]Y. Hara, K. Fujimoto, H. Mayama, Self-oscillation of polymer chains with an Fe(bpy)3 catalyst induced by the Belousov-Zhabotinsky reaction. J. Phys. Chem. B 118 (2014) 608-612.

[16] Y. Hara, H. Mayama, K. Fujimoto, Influence of Belousov-Zhabotinsky substrate concentrations on autonomous oscillation of polymer chains with $\mathrm{Fe}(\mathrm{bpy})_{3}$ catalyst. J. Phys. Chem. B 118 (2014) 6931-6936.

[17] Y. Hara, Y. Takenaka, Autonomous oscillation of polymer chains induced by the Belousov-Zhabotinsky reaction. Sensors. 14 (2014) 1497-1510. 